\title{
Association of abnormal placental perfusion with the risk of male hypospadias: a hospital-based retrospective cohort study
}

\author{
Chen Zhu' ${ }^{1}$ Bin Zhang ${ }^{2}$, Ting Peng ${ }^{2}$, Ming-Qing Li, ${ }^{3,4}$, Yun-Yun Ren ${ }^{1^{*}}$ and Jiang-Nan Wu ${ }^{5^{*}}$ (D
}

\begin{abstract}
Background: The effect and extent of abnormal placental perfusion (APP) on the risk of male hypospadias are poorly understood. We compared the prevalence of male hypospadias in the offspring of women with APP and quantify the extent of the APP effect on the anomaly.

Methods: A hospital-based retrospective analysis of births from 2012 to 2016 was conducted in 2018. Women of singleton pregnancy and male infants born to them were included $(N=21,447)$. A multivariate analysis was performed to compare the prevalence of male hypospadias in infants exposed to APP with those that were not exposed to APP.

Results: Compared with the infants of women without APP, infants of women with APP showed an increased risk of male hypospadias (odds ratio, 2.40; 95\% confidence interval, 1.09-5.29). The male hypospadias cumulative risk increased with the severity of APP. Infants exposed to severe APP had a significantly higher risk of male hypospadias than those without APP exposure (9.2 versus 1.7 per 1000 infants, $P<0.001$ ). A path analysis indicated that 28.18$46.61 \%$ of the risk of hypospadias may be attributed to the effect of APP.
\end{abstract}

Conclusions: Male hypospadias risk was associated with APP and increased with APP severity, as measured in the second trimester. APP had an important role in the development of the anomaly.

Keywords: Hypospadias, Abnormal placental perfusion, Uterine artery, Preeclampsia, Retrospective cohort study

\section{Background}

Hypospadias are one of the most common birth defects in infants and have a substantial impact on childhood renal survival and the quality of life of affected children [1-3]. For example, infants with hypospadias may suffer from complications later in life, including a higher risk of testicular cancer and subfertility $[4,5]$, despite corrective surgery treatment. Furthermore, the prevalence of the anomaly in

\footnotetext{
* Correspondence: renyunyun@hotmail.com; wjnhmm@126.com 'Department of Ultrasound, Obstetrics and Gynecology Hospital, Fudan University, 419 Fangxie Road, Shanghai 200011, China

${ }^{5}$ Department of Clinical Epidemiology, Obstetrics and Gynecology Hospital, Fudan University, 566 Fangxie Road, Shanghai 200011, China

Full list of author information is available at the end of the article
}

China is increasing [6]. According to the Report on the Prevention and Treatment of Birth Defects in China (2012), the prevalence of hypospadias has increased from 3.08 per 10,000 births in 1996 to 5.03 per 10,000 births in 2011 and ranks sixth among all birth defects in 2011 [7]. However, the causes of hypospadias are mostly unknown.

Placental dysfunction was considered a plausible candidate cause of congenital anomalies, such as hypospadias and congenital heart defects, because placental dysfunction may cause inadequate fetal hCG provision and intrauterine growth restriction and associate with angiogenic imbalance $[3,8,9]$. Placental dysfunction is often observed in pregnancies that are complicated by preeclampsia $(\mathrm{PE})$,

(C) The Author(s). 2020 Open Access This article is licensed under a Creative Commons Attribution 4.0 International License, which permits use, sharing, adaptation, distribution and reproduction in any medium or format, as long as you give appropriate credit to the original author(s) and the source, provide a link to the Creative Commons licence, and indicate if changes were made. The images or other third party material in this article are included in the article's Creative Commons licence, unless indicated otherwise in a credit line to the material. If material is not included in the article's Creative Commons licence and your intended use is not permitted by statutory regulation or exceeds the permitted use, you will need to obtain permission directly from the copyright holder. To view a copy of this licence, visit http://creativecommons.org/licenses/by/4.0/ The Creative Commons Public Domain Dedication waiver (http://creativecommons.org/publicdomain/zero/1.0/) applies to the data made available in this article, unless otherwise stated in a credit line to the data. 
and markers of placental perfusion and function, such as uterine artery (UtA) pulsatility index (PI) and placental growth factor, therefore, have been employed to screen for PE [9-11], which was previously determined to be associated with the risk of cryptorchidism and hypospadias [12-15]. However, whether the cause of hypospadias is of placental origin or maternal genetic origin is still uncertain. Therefore, we conducted a retrospective cohort study to determine the relationship between abnormal placental perfusion (APP) and the risk of male hypospadias and quantify the extent of the effect of placental origin (indicated by APP, including UtA-PI, resistance index [RI], and early diastolic notching [EDN]) and maternal genetic origin (represented by PE, since PE has recently been observed as a maternal genetic origin disorder rather than the long-held viewpoint that PE is a placental disorder [16-18]).

\section{Methods}

\section{Data and study design}

We conducted a hospital-based retrospective study of pregnant women who received prenatal examinations at the hospital between April 2012 and August 2016 in Shanghai, China. Details of the design and methods have been described elsewhere [19]. Briefly, birth defect outcomes, including hypospadias, for infants reported in the Chinese Birth Defect Surveillance Network and in the Shanghai Perinatal Statistics Collection System were extracted and matched with hospital discharge reports for pregnant women that were compiled in the hospital electronic medical record system according to the unique identity card number of each mother. All women with singleton pregnancy of male fetuses were included in the study. The study was approved by the Ethics Committee of the Obstetrics and Gynecology Hospital of Fudan University (No. 201735, 2017-35-C1).

\section{Male hypospadias}

Male hypospadias was diagnosed by clinicians according to the routine comprehensive physical examination for infants after delivery and was recorded in the medical information system [19]. Details of the anomaly were further collected to classify hypospadias as anterior hypospadias, middle hypospadias, and posterior hypospadias, as well as an unknown type when no details were available.

\section{Placental perfusion measurement and definition}

Measurement of the UtA was recommended for pregnant women to screen for major organ malformations at 20 to 24 weeks gestation. All ultrasound scans were conducted using the GE Voluson-E6 and GE Voluson-E8 ultrasound devices (GE Healthcare, Zipf, Austria). Doppler measurements of the UtA were obtained by sonographers who have hold color Doppler large-scale instrument qualification certification according to standardized protocols [20]. Measurements for both UtA-PI and UtA-RI were calculated, and the presence of EDN was recorded. Therefore, there were six placental perfusion markers, including right and left UtA-PI, UtA-RI and EDN.

The quality of UtA-PI measurement, which was assessed by $95 \%$ limits of agreement using a randomly sample of 50 women, has shown that the measurement had a reasonable intra- and interoperator measurement repeatability (data not shown). Since the distribution of the UtA-PI and -RI values were nonnormal, the ninetyfifth percentile (P 95) of the values by gestational weeks at the time of the measurement was used to classify pregnant women into high (>P 95) UtA-PI and UtA-RI groups and normal $(\leq$ P95) UtA-PI and UtA-RI groups. Data of P 95 for the four UtA indices by gestational weeks are shown in Table S1. UtA-EDN was diagnosed according to the ISUOG practice guidelines [20]. APP was defined by any abnormal values for the six markers (e.g., high right UtA-PI or -RI, high left UtA-PI or -RI, or positive for right or left UtA-EDN). Pregnant women who did not participate in uterine artery measurement were classified as the missing APP group.

\section{Covariates}

$\mathrm{PE}$ is defined as the onset of hypertension and proteinuria after 20 weeks of gestation in women who were previously normotensive [21]. Pregnant women with PE were further identified as having severe $\mathrm{PE}$ if a continuous elevation of blood pressure (e.g., systolic blood pressure $\geq 160 \mathrm{mmHg}$, and/or diastolic blood pressure $\geq 110 \mathrm{mmHg}$ ) and/or urinary protein level (e.g., $>2.0 \mathrm{~g} / 24 \mathrm{~h}$ ), impaired maternal organ function (e.g., abnormal liver enzymes, dysopsia), or placental-fetal complications (e.g., fetal growth restriction, oligohydramnios) occurred [21]. Patients with eclampsia (an advanced form of PE that is characterized by convulsions of unexplained causes) were also included as severe PE (only 4 cases). Gestational hypertension (hypertension that develops after 20 weeks of gestation without proteinuria, 899 cases) and chronic hypertension with superimposed PE (new onset of proteinuria among women with preexisting hypertension, 308 cases) were classified as mild PE, as indicated in a previous study [22]. Women with chronic hypertension-complicated pregnancies (126 cases) were classified as no PE.

Potential confounders, including maternal age at delivery ( $\leq 24,25-34$, and $\geq 35$ years), resident location (Shanghai and other provinces), parity (nulliparous and multiparous), assisted conception (yes and no), gestational diabetes mellitus (GDM, yes and no) and fetal gender (male and female), were extracted from the discharge reports. GDM was defined based on a $75 \mathrm{~g}$ oral glucose tolerance test [23]. Assisted conception pregnancies referred to pregnancies 
from in vitro fertilization or intracytoplasmic sperm injection and were self-reported from the pregnant women [19].

\section{Data analysis}

The prevalence of hypospadias per 1000 infants and the corresponding 95\% confidence interval (CI) for women with and without APP were calculated and compared using the chi-square test or Fisher's exact test. Logistic regression models were created to estimate the crude odds ratios (ORs) and 95\% CIs for hypospadias among infants who were exposed to APP compared with those without APP. Adjusted ORs and 95\% CIs were evaluated after controlling for PE, maternal age at delivery, resident location, parity, mode of conception, GDM and fetal gender.

The relationships between variant APP (defined by any of the six markers) and the risk of male hypospadias were estimated. Pregnant women with APP were further grouped into mild (any 1 abnormal marker), moderate (any 2 abnormal marker) and severe ( $\geq 3$ abnormal markers) APP subgroups according to the abnormal number of the six markers. The cumulative risk of male hypospadias across the three APP subgroups was calculated and compared with that in pregnant women without APP by the KaplanMeier curve method. A posteriori analysis was conducted in estimating the association between the risk of male hypospadias and APP classified by the situation of left UtA-RI and UtA-EDN, since it was accidentally determined that the two markers had stronger associations with the risk of male hypospadias than the other four markers.

Logistic regression analyses using path analysis models were conducted to decompose the total risk of male hypospadias into the effect of PE (presumed to be a maternal genetic effect) and the effect of APP (as a placental effect). We assumed two causal chains since the two factors were related. In path analysis, PE was set as a direct factor, and APP was set as an indirect factor, and vice versa [24]. The results of the path analyses were then combined according to the weight of the coefficient to explain the extent of the effect of APP if both PE and APP were directly and significantly associated with the risk of male hypospadias.

We restricted the sensitivity analyses to nulliparous women and those of natural conception because multiparity and assisted conception births may affect the severity of APP and may be associated with the risk of male hypospadias. Path analysis models were performed with Stata 12 software. All other statistical tests were conducted using IBM SPSS Statistics version 22.0. A two-sided $P$ value $<0.05$ was considered statistically significant.

\section{Results}

Basic characteristics of the study participants

A total of 52,047 pregnant women were involved in pregnancy examinations at the hospital between April 2012 and August 2016. Among these women, 21,447 (41.2\%) pregnant women with a male fetus singleton pregnancy were included in this study. A total of 1861 pregnant women $(8.7 \%)$ were classified as APP, and 1172 women (5.5\%) were diagnosed with $\mathrm{PE}$, including 212 women with severe PE (1.0\%).

\section{Prevalence of male hypospadias}

A total of 43 fetuses complicated with hypospadias were identified in this study, with an overall prevalence of male hypospadias of 2.5 per 1000 infants (95\% CI, 1.8-3.3). The prevalence of hypospadias was higher for the infants of the women with APP than those of the women without APP (4.8 versus 1.7 per 1000 infants, $P=.01$ ) (Table 1 ). Most of the cases $(76.7 \%, 33 / 43)$ involved the unknown type. Of the remaining 10 cases, 6 cases involved anterior hypospadias, 3 cases involved midline hypospadias and 1 case involved posterior hypospadias, which accounts for 60,30 and $10 \%$, respectively, of the cases.

\section{Association between APP and male hypospadias}

Table 2 shows the association between APP and the risk of male hypospadias. Compared with the infants of the women without APP, the infants born to the women with APP were significantly associated with an increased risk of male hypospadias (OR, 2.40; 95\% CI, 1.09-5.29). In the sensitivity analyses restricted to nulliparous and natural conception women, the association of APP with the risk of male hypospadias did not produce significantly different results (Table S2).

The association of the variants of APP with male hypospadias varied (Table 3). Women with a high left UtA-RI had an increased risk of having infants with hypospadias (OR, 2.86; 95\% CI, 1.06-7.70) relative to those with normal RI. Women with left UtA-EDN were also associated with the risk of male hypospadias (OR, 5.33; 95\% CI, 1.56-18.26) relative to those without left UtA-EDN.

The cumulative risk of male hypospadias among infants who were exposed to severe APP was higher than that among infants without APP exposure (9.20 versus 1.69 per 1000 infants, $P<0.001$ ) (Fig. 1). However, no significant association between severe APP with male hypospadias was observed in the multivariate regression models (Table 3). Restricting APP to left UtA-RI and UtA-EDN led to much stronger associations with male hypospadias. Women who had both high RI and EDN had a higher cumulative risk of producing fetuses with hypospadias (13.33 vs 1.72 per 1000 infants, $P=.005$ ) than those with normal left UtA-RI and UtA-EDN, but there was no significant association with the risk of male hypospadias (Fig. 1, Table 3).

\section{Effect of APP on the risk of male hypospadias}

Table 4 summarizes the results of the effect of APP on the risk of male hypospadias. Both PE and APP had a role in male hypospadias, with a total risk of $46.61 \%$ for 
Table 1 Characteristics and prevalence of male hypospadias

\begin{tabular}{|c|c|c|c|c|c|}
\hline \multirow{2}{*}{\multicolumn{2}{|c|}{ Characteristics }} & \multicolumn{4}{|c|}{ Male Hypospadias ( $n=21,447$, cases $=43$ ) } \\
\hline & & Total no. of infants & No. of cases & Prevalence per 1000 infants $(95 \% \mathrm{Cl})$ & $P$ value \\
\hline \multicolumn{2}{|c|}{ Placental perfusion $^{a}$} & & & & .03 \\
\hline \multicolumn{2}{|l|}{ Normal } & 14,186 & 24 & $1.7(1.0-2.4)$ & \\
\hline \multicolumn{2}{|l|}{ Abnormal } & 1861 & 9 & $4.8(1.7-8.0)$ & $.01^{\mathrm{b}}$ \\
\hline \multicolumn{2}{|l|}{ NA } & 5400 & 10 & $1.9(0.7-3.0)$ & .81 \\
\hline \multicolumn{2}{|l|}{ Preeclampsia } & & & & .001 \\
\hline \multicolumn{2}{|l|}{ No } & 20,275 & 36 & $1.8(1.2-2.4)$ & \\
\hline \multirow[t]{3}{*}{ Yes } & Mild & 960 & 3 & $3.1(0.0-6.7)$ & $.26^{\mathrm{b}}$ \\
\hline & Severe & 212 & 4 & $18.9(0.4-37.3)$ & $.001^{b}$ \\
\hline & Any & 1172 & 7 & $6.0(1.6-10.4)$ & $.008^{\mathrm{b}}$ \\
\hline \multicolumn{3}{|c|}{ Maternal age at delivery (year) } & & & $.34^{\mathrm{b}}$ \\
\hline \multicolumn{2}{|l|}{$\geq 35$} & 2145 & 5 & $2.3(0.3-4.4)$ & \\
\hline \multicolumn{2}{|l|}{$25-34$} & 18,224 & 38 & $2.1(1.4-2.7)$ & \\
\hline \multicolumn{2}{|l|}{$<25$} & 1078 & 0 & 0 & \\
\hline \multicolumn{2}{|l|}{ Residence } & & & & .59 \\
\hline \multicolumn{2}{|l|}{ Shanghai } & 16,536 & 35 & $2.1(1.4-2.8)$ & \\
\hline \multicolumn{2}{|c|}{ Other provinces } & 4884 & 8 & $1.6(0.5-2.8)$ & \\
\hline \multicolumn{2}{|l|}{ Parity } & & & & .14 \\
\hline \multicolumn{2}{|l|}{ Nulliparous } & 18,099 & 40 & $2.2(1.5-2.9)$ & \\
\hline \multicolumn{2}{|l|}{ Multiparous } & 3348 & 3 & $0.9(0.0-1.9)$ & \\
\hline \multicolumn{2}{|c|}{ Gestational diabetes mellitus } & & & & $>.99^{\mathrm{b}}$ \\
\hline \multicolumn{2}{|l|}{ No } & 19,616 & 40 & $2.0(1.4-2.7)$ & \\
\hline \multicolumn{2}{|l|}{ Yes } & 1831 & 3 & $1.6(0.0-3.5)$ & \\
\hline \multicolumn{2}{|c|}{ Assisted conception } & & & & $.18^{\mathrm{b}}$ \\
\hline \multicolumn{2}{|l|}{ No } & 21,061 & 41 & $1.9(1.4-2.5)$ & \\
\hline \multicolumn{2}{|l|}{ Yes } & 386 & 2 & $5.2(0.0-12.3)$ & \\
\hline
\end{tabular}

NA APP data not available

${ }^{a}$ Abnormal perfusion insufficiency was defined as any one abnormality of the six markers, which otherwise were normal; ${ }^{b} P$ values for Fisher's exact tests

male hypospadias, which may be attributed to the effect of APP in the total sample. Among women with severe PE and APP, the effect of APP on the risk of male hypospadias decreased to $28.18 \%$, while neither mild PE nor APP was associated with the risk of male hypospadias among women with mild PE and APP (Table 4).

\section{Discussion}

In this retrospective cohort study of 21,447 single pregnancy Chinese women, the risk of fetal male hypospadias was associated with APP and increased with the severity of APP. Among the variants of APP, APP defined by a high left UtA-RI and positive EDN appeared to be most strongly associated with the risk of the anomaly. Compared with PE, APP had a mild-to-moderate role in the pathogenesis of male hypospadias, which accounts for $28.18-46.61 \%$ of the risk of male hypospadias. These findings confirmed the relationship between APP and the risk of male hypospadias and provided evidence for exploring the pathogenesis of the anomaly and the clinical screening and management of the disease.

\section{Context within previous literature}

Early placental insufficiency was suggested as a plausible candidate cause for congenital anomalies in boys due to the vulnerable time window of genital morphogenesis in the first trimester [15]. Markers of placental insufficiency were considered linked with the risk of hypospadias. Placental weight and other placental characteristics and markers of placental insufficiency were examined in relation to hypospadias by Ghazarian AA and the colleagues using the Collaborative Perinatal Project [25]. However, except for placenta calcification, neither placental weight nor other placental characteristics (e.g., placental thickness, placental infarcts, amnion cell metaplasia, changes to the intervillous space, and intervillous thrombosis) were linked to the risk of hypospadias [25]. 
Table $\mathbf{2}$ Odds ratios of male hypospadias

\begin{tabular}{|c|c|c|c|}
\hline \multirow[t]{2}{*}{ Characteristics } & & \multicolumn{2}{|l|}{ Male hypospadias } \\
\hline & & Crude odds ratio $(95 \% \mathrm{Cl})$ & Adjusted odds ratio $(95 \% \mathrm{Cl})$ \\
\hline \multicolumn{4}{|l|}{ Placental perfusion } \\
\hline Normal & & 1.00 & 1.00 \\
\hline Abnormal ${ }^{a}$ & & $2.87(1.33-6.18)$ & $2.40(1.09-5.29)$ \\
\hline NA & & $1.10(0.52-2.29)$ & $1.12(0.53-2.37)$ \\
\hline \multicolumn{4}{|l|}{ Preeclampsia } \\
\hline No & & 1.00 & 1.00 \\
\hline \multirow[t]{2}{*}{ Yes } & Mild & $1.76(0.54-5.73)$ & $1.56(0.47-5.11)$ \\
\hline & Severe & $10.81(3.82-30.66)$ & $7.75(2.62-22.89)$ \\
\hline \multicolumn{4}{|c|}{ Maternal age at delivery (years) } \\
\hline$\geq 35$ & & 1.00 & 1.00 \\
\hline $25-34$ & & $0.89(0.35-2.27)$ & $0.74(0.27-1.99)$ \\
\hline$<25$ & & - & - \\
\hline \multicolumn{4}{|l|}{ Residence } \\
\hline Shanghai & & 1.00 & 1.00 \\
\hline Other provinces & & $0.78(0.36-1.67)$ & $0.90(0.41-1.96)$ \\
\hline \multicolumn{4}{|l|}{ Parity } \\
\hline Nulliparous & & 1.00 & 1.00 \\
\hline Multiparous & & $0.41(0.13-1.31)$ & $0.39(0.11-1.33)$ \\
\hline \multicolumn{4}{|c|}{ Gestational diabetes mellitus } \\
\hline No & & 1.00 & 1.00 \\
\hline Yes & & $0.80(0.25-2.60)$ & $0.68(0.21-2.23)$ \\
\hline \multicolumn{4}{|l|}{ Assisted conception } \\
\hline No & & 1.00 & 1.00 \\
\hline Yes & & $2.66(0.64-11.02)$ & $1.96(0.45-8.55)$ \\
\hline
\end{tabular}

Impaired uteroplacental circulation is also a marker of placental insufficiency and has a central role in the pathogenesis of neonatal complications [26-29]. APP may be a consequent manifestation of defective or absent remodeling of the myometrial segment of the uteroplacental arteries [28-30] and accompanying placental dysfunction [31-33]. Placental insufficiency may cause inadequate fetal hCG provision, which is important for genitourinary development in the first trimester since hCG may stimulate fetal testicular steroidogenesis before the fetal pituitary-gonadal axis is established $[3,25,34$, 35]. Furthermore, the severity of APP was positively correlated with placental apoptosis and associated with an increased rate of preterm delivery and small-forgestational age at birth [36]; both conditions are wellknown and strong predictors of cryptorchidism and hypospadias [37, 38].

In this study, we discovered that both APP and PE were significantly associated with male hypospadias. These findings did not support that PE might only be a placental origin complication, which was consistent with a growing body of evidence that supports the role of maternal genetic origin in the pathogenesis of PE $[16-18,39]$. We then introduced PE as a novel maternal factor in the pathogenesis model of male hypospadias and decomposed the total risk of male hypospadias into components of maternal and placental origin. We discovered that $53.39 \%(=1-46.61 \%)$ to $71.82 \%(=1-28.18 \%)$ of the risk of male hypospadias may be attributed to maternal (severe) PE. These findings were consistent with the results of previous studies, which revealed that genetic origin has a principal role in causing hypospadias and accounts for 57 to $77 \%$ of the phenotypic variability [3, 40-42]. APP, separately and/or through its association with $\mathrm{PE}$, had a role in the risk of male hypospadias. The findings suggested a predominantly maternal genetic origin effect on the risk of male hypospadias [43].

\section{Implications of the study}

Our findings help advance the understanding of the role of APP and PE in the pathogenesis of male hypospadias 
Table 3 Variant of abnormal placental perfusion and odds ratio of male hypospadias

\begin{tabular}{|c|c|c|c|c|}
\hline \multicolumn{2}{|c|}{ Variant of abnormal placental perfusion } & \multicolumn{3}{|c|}{ Male hypospadias } \\
\hline & & No. of infants & No. of cases & Adjusted odds ratio $(95 \% \mathrm{Cl})$ \\
\hline \multicolumn{5}{|c|}{ Right uterine artery } \\
\hline \multirow[t]{2}{*}{$\mathrm{Pl}$} & Normal (SP95) & 15,244 & 28 & 1.00 \\
\hline & High (>P95) & 835 & 5 & $2.60(0.97-6.98)$ \\
\hline \multirow[t]{2}{*}{$\mathrm{Rl}$} & Normal ( $\leq$ P95) & 15,348 & 29 & 1.00 \\
\hline & High (>P95) & 731 & 4 & $2.34(0.80-6.85)$ \\
\hline \multirow[t]{2}{*}{ EDN } & No & 15,942 & 32 & 1.00 \\
\hline & Yes & 144 & 1 & $2.27(0.29-17.65)$ \\
\hline \multicolumn{5}{|c|}{ Left uterine artery } \\
\hline \multirow[t]{2}{*}{$\mathrm{Pl}$} & Normal $(\leq \mathrm{P} 95)$ & 15,218 & 28 & 1.00 \\
\hline & High (>P95) & 839 & 4 & $2.03(0.68-5.99)$ \\
\hline \multirow[t]{2}{*}{$\mathrm{Rl}$} & Normal ( $\leq$ P95) & 15,267 & 27 & 1.00 \\
\hline & High (>P95) & 790 & 5 & $2.86(1.06-7.70)$ \\
\hline \multirow[t]{2}{*}{ EDN } & No & 15,859 & 30 & 1.00 \\
\hline & Yes & 226 & 3 & $5.33(1.56-18.26)$ \\
\hline \multicolumn{5}{|c|}{ No. of insufficient markers } \\
\hline \multicolumn{2}{|l|}{0} & 14,186 & 24 & 1.00 \\
\hline \multicolumn{2}{|l|}{1} & 663 & 3 & $2.50(0.75-8.34)$ \\
\hline \multicolumn{2}{|l|}{2} & 872 & 3 & $1.79(0.53-6.04)$ \\
\hline \multicolumn{2}{|c|}{3 and above } & 326 & 3 & $3.59(0.99-12.95)$ \\
\hline \multicolumn{5}{|c|}{ Left uterine artery RI and EDN } \\
\hline \multicolumn{2}{|c|}{ Normal RI and without EDN } & 15,112 & 26 & 1.00 \\
\hline \multicolumn{2}{|c|}{ High RI or with EDN } & 866 & 6 & $3.35(1.34-8.38)$ \\
\hline \multicolumn{2}{|c|}{ High RI and with EDN } & 75 & 1 & $6.33(0.68-41.70)$ \\
\hline \multicolumn{2}{|c|}{ Any of high RI and/or with EDN } & 941 & 7 & $3.53(1.48-8.41)$ \\
\hline
\end{tabular}

PI Pulsatility index, RI Resistance index, EDN Early diastolic notching
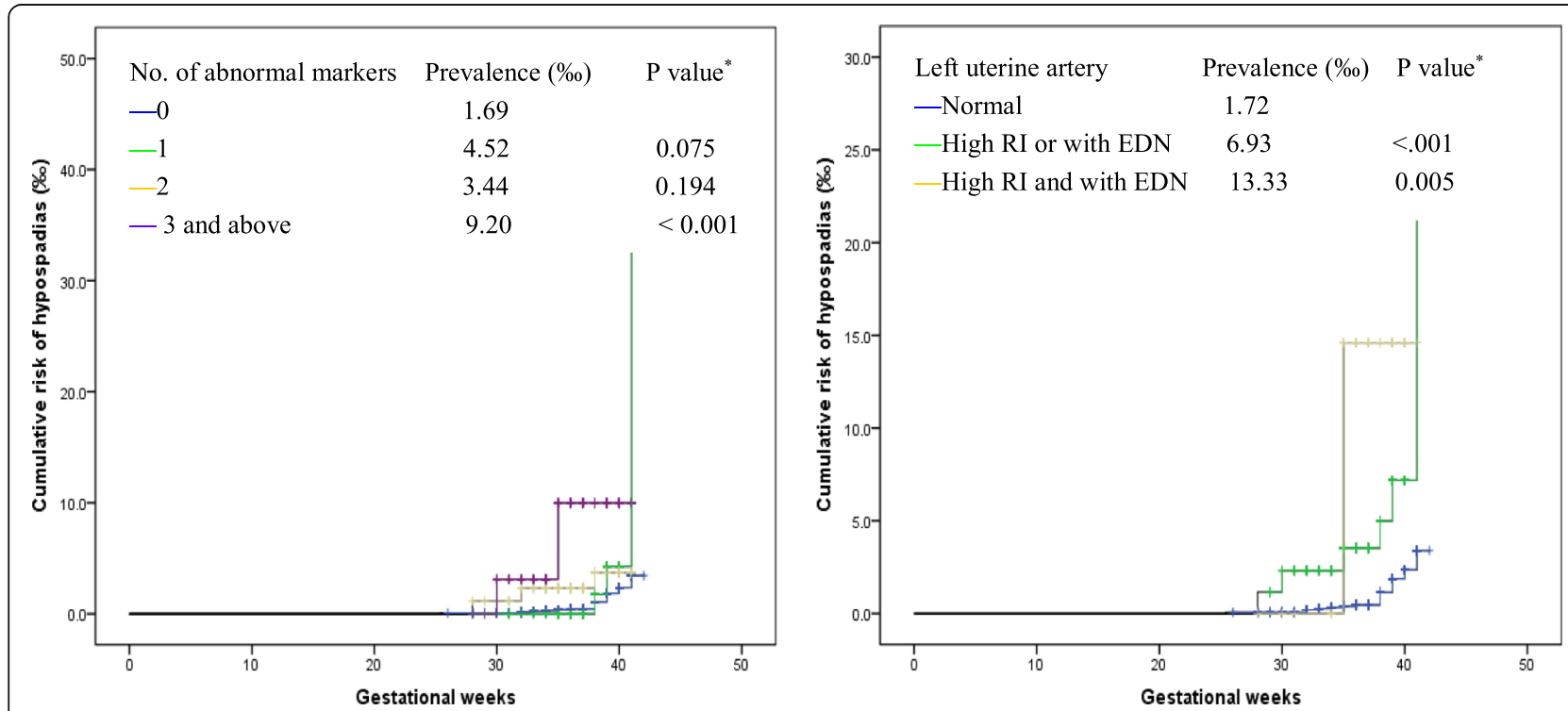

Fig. 1 Cumulative risk of male hypospadias across the groups by the number of placental perfusion insufficiency markers and the situation of left uterine artery resistance index (RI) and early diastolic notching (EDN). * $P$ values for the log rank (Mantel-Cox) method compared with the cumulative risk of male hypospadias in the reference group 
Table 4 Estimated size of the effect of abnormal placental perfusion on the risk of male hypospadias (\%)

\begin{tabular}{|c|c|c|c|c|c|c|c|c|}
\hline \multirow[t]{2}{*}{ No. of population } & \multirow{2}{*}{$\begin{array}{l}\text { Direct factor } \\
\text { (causal chain }^{\text {b) }}\end{array}$} & \multicolumn{3}{|c|}{ Total effect } & \multicolumn{4}{|c|}{ The effect of abnormal placental perfusion } \\
\hline & & Coef. & Standard Error & $P$ value & Coef. & Standard Error & $P$ value & Size of the total effect (\%) \\
\hline \multirow{3}{*}{$\begin{array}{l}\text { Infants (16051), any PE (874), } \\
\text { APP (1861), anomalies (33) }\end{array}$} & Any PE (1) & 1.30 & 0.49 & .007 & 0.15 & 0.06 & .009 & 11.54 \\
\hline & $\operatorname{APP}(2)$ & 1.06 & 0.36 & .003 & 0.95 & 0.34 & .006 & 89.62 \\
\hline & Total (3) & 2.36 & & & 1.10 & & & 46.61 \\
\hline \multirow{3}{*}{$\begin{array}{l}\text { Infants (15903), mild PE (726), } \\
\text { APP (1792), anomalies (29) }\end{array}$} & Mild PE (1) & 0.36 & 0.60 & .54 & 0.04 & 0.05 & .37 & 11.11 \\
\hline & $\operatorname{APP}(2)$ & 0.50 & 0.56 & .38 & 0.49 & 0.55 & .37 & 98.00 \\
\hline & Total (3) & 0.86 & & & 0.53 & & & 61.63 \\
\hline \multirow{3}{*}{$\begin{array}{l}\text { Infants (15325), severe PE (148), } \\
\text { APP (1730), anomalies (31) }\end{array}$} & Severe PE (1) & 2.68 & 0.60 & $<.001$ & 0.30 & 0.16 & .07 & 11.19 \\
\hline & APP (2) & 1.01 & 0.35 & .004 & 0.74 & 0.31 & .02 & 73.27 \\
\hline & Total (3) & 3.69 & & & 1.04 & & & 28.18 \\
\hline
\end{tabular}

PE Preeclampsia, APP Abnormal placental perfusion

${ }^{a}$ Adjusted for maternal age at delivery $(<25,25-34$, or $\geq 35)$, residence (Shanghai or other provinces), parity (nulliparous or multiparous), gestational diabetes

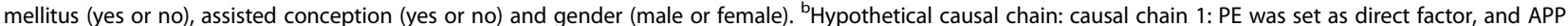
as indirect factor; causal chain 2: APP as direct factor and PE as indirect factor; causal chain 3: the weight of the coefficient of the effect of APP in chains 1 and 2 was combined when both of the causal chains $(1$ and 2$)$ work ( $p$ value for the coeefficient $<0.05)$

and have clinical value for management of the anomaly. First, the effect of PE on the risk of male hypospadias supports a predominantly maternal genetic origin-ofeffect. Therefore, the prevention of hypospadias may predominantly depend on the ability to elucidate maternal genetic origin risk. Second, the association of APP with male hypospadias revealed that placental perfusion measurement may have a more valuable role in management of the disease, although the placental perfusion measurement might not have high predictive value for anomalies because of the fairly low prevalence of the outcomes. Thus, strategies for placental perfusion measurement should be optimized, including recognizing the necessity of measurement for obstetrics and recommending this procedure for all pregnant women. For people at high risk of male hypospadias, such as women with severe APP or at least one abnormality of left UtARI or UtA-EDN, further examinations of the fetal urogenital system are needed for the early detection and management of ongoing urogenital injury. These measures are particularly important in the context of the strict ban on sex determination by ultrasound and the rising prevalence rate of hypospadias in China.

\section{Limitations}

There were some limitations in our study. First, the prevalence of infantile male hypospadias may be underestimated since $20 \%$ of the sample was lost to follow-up and possibly included women with miscarriages and terminated pregnancies. Fetuses born from these women were considered to have a high prevalence of birth defects [44, 45]. However, the association between APP and male hypospadias should not be affected by the underestimation. Second, $25.1 \%$ of the women did not participate in the placental perfusion measurement since the measurement was optional, and the infants born to these women might have an increased risk of infantile hypospadias, which suggests that women without APP measurements may have some characteristics associated with the disease. We were not able to estimate the potential impact of these characteristics on the associations between APP and hypospadias. However, we did not believe that these characteristics would affect the association between APP and hypospadias since the association was statistically significant in the logistic regression model, sensitivity analysis and path analysis. Third, details on pathology and phenotype were not available for further analysis and identification. For example, most of the cases (76.7\%) were identified as the unknown type, and only one case underwent a pathological examination of the placenta (results showed APP, mild decidualitism, and placental villous stromal angioplasia with dilation). We were not able to link the findings and severity of the anomaly to understand the underlying pathophysiology. Furthermore, studies on the differences in relation to the risk of hypospadias across the six UtA indices were needed. Last, although the sample size was relatively large, this study was a single-center study of pregnant women in Shanghai, which might limit the generalizability of the findings.

\section{Conclusions}

In this retrospective cohort study of single pregnancy Chinese women, we discovered that the risk of male hypospadias was associated with APP and increased with the severity of APP measured in the second trimester. APP had a mild-to-moderate effect on the risk of hypospadias compared with the role of PE. 


\section{Supplementary Information}

The online version contains supplementary material available at https://doi. org/10.1186/s12884-020-03381-1.

Additional file 1: Table S1. The ninety-fifth percentile (P95) of the values of the left and right uterine artery pulsatility index (PI) and resistance index (RI) by gestational week.

Additional file 2: Table S2. Odds ratio of male hypospadias in nulliparous and natural conception pregnant women.

\section{Abbreviations}

APP: Abnormal placental perfusion; Cl: Confidence interval; OR: Odds ratio; PE: Preeclampsia; PI: Pulsatility index; RI: Resistance index; UtA: Uterine artery; EDN: Early diastolic notching

\section{Acknowledgements}

We would like to thank all the infants and families who made the study possible.

\section{Authors' contributions}

JNW and YYR were responsible for conception of the study, data analysis and interpretation of findings. JNW and CZ advised on design. JNW, CZ, BZ, $\mathrm{MQL}$ and TP collected the data. JNW analysed the data and interpreted the findings. JNW and CZ drafted the manuscript. JNW and YYR reviewed and edited the final draft. All authors approved the final draft.

\section{Funding}

No funding was received for the study.

\section{Availability of data and materials}

The datasets used in present study available from the corresponding author (wjnhmm@126.com) on reasonable request only.

\section{Ethics approval and consent to participate}

The study was approved by the Ethics Committee of the Obstetrics and Gynecology Hospital of Fudan University (No. 2017-35, 2017-35-C1) and was conducted in accordance with Chinese law and the Guidelines of the National Human Biomedical Research Policies. No informed consent was obtained from the patients because the study was retrospective. Administrative permissions of the data was acquired by the authors for research purposes.

\section{Consent for publication}

Not applicable.

\section{Competing interests}

The authors declare that they have no competing interests.

\section{Author details}

'Department of Ultrasound, Obstetrics and Gynecology Hospital, Fudan University, 419 Fangxie Road, Shanghai 200011, China. 'Department of Obstetrics, Obstetrics and Gynecology Hospital, Fudan University, Shanghai, China. ${ }^{3}$ Research institute of Obstetrics and Gynecology Hospital, Fudan University, Shanghai, China. ${ }^{4}$ Shanghai Key Laboratory of Female Reproductive Endocrine-Related Diseases, Shanghai, China. ${ }^{5}$ Department of Clinical Epidemiology, Obstetrics and Gynecology Hospital, Fudan University, 566 Fangxie Road, Shanghai 200011, China.

Received: 11 June 2020 Accepted: 29 October 2020

\section{Published online: 07 November 2020}

\section{References}

1. Chesnaye NC, Schaefer F, Bonthuis M, et al. Mortality risk disparities in children receiving chronic renal replacement therapy for the treatment of end-stage renal disease across Europe: an ESPN-ERA/EDTA registry analysis. Lancet. 2017;389:2128-37.

2. Wuhl E, van Stralen KJ, Verrina E, et al. Timing and outcome of renal replacement therapy in patients with congenital malformations of the kidney and urinary tract. Clin J Am Soc Nephrol. 2013;8:67-74.
3. van der Zanden LF, van Rooij IA, Feitz WF, et al. Aetiology of hypospadias: a systematic review of genes and environment. Hum Reprod Update. 2012;18:260-83.

4. Trabert B, Zugna D, Richiardi L, McGlynn KA, Akre O. Congenital malformations and testicular germ cell tumors. Int J Cancer. 2013;133(8):1900-4.

5. Serrano T, Chevrier C, Multigner L, Cordier S, Jegou B. International geographic correlation study of the prevalence of disorders of male reproductive health. Hum Reprod. 2013;28:1974-86.

6. Sun G, Tang D, Liang J, Wu M. Increasing prevalence of hypospadias associated with various perinatal risk factors in chinese newborns. Urology. 2009:73:1241-5.

7. Ministry of Health of the People's Republic of China. Report on prevention and treatment of birth defects in China (2012). http://www.moh.gov.cn/ wsb/pxwfb/201209/55840.shtml. Accessed 12 Sept 2012.

8. Llurba E, Sanchez O, Ferrer Q, et al. Maternal and foetal angiogenic imbalance in congenital heart defects. Eur Heart J. 2014;35:701-7.

9. Sliwa K, Mebazaa A. Possible joint pathways of early pre-eclampsia and congenital heart defects via angiogenic imbalance and potential evidence for cardio-placental syndrome. Eur Heart J. 2014;35:680-2.

10. Zeisler $\mathrm{H}$, Llurba E, Chantraine F, et al. Predictive value of the sFlt-1:PIGF ratio in women with suspected preeclampsia. N Engl J Med. 2016;374:13-22.

11. Zeisler H, Llurba E, Chantraine F, et al. Soluble fms-like tyrosine Kinase-1-toplacental growth factor ratio and time to delivery in women with suspected preeclampsia. Obstet Gynecol. 2016;128:261-9.

12. Van Zutphen AR, Werler MM, Browne MM, Romitte PA, Bell EM, McNutt LA, Druschel CM, Mitchell AA. National Birht Defects Prevention Study. Maternal hypertension, medication use, and hypospadias in the National Birth Defects Prevention Study. Obstet Gynecol. 2014;123:309-17.

13. Nelson DB, Chalak LF, McIntire DD, Leveno KJ. Is preeclampsia associated with fetal malformation? A review and report of original research. J Matern Fetal Neonatal Med. 2015;28:2135-40.

14. van Gelder MM, Van Bennekom CM, Louik C, Werler MM, Roeleveld N, Mitchell AA. Maternal hypertensive disorders, antihypertensive medication use, and the risk of birth defects: a case-control study. BJOG. 2015;122:1002-9.

15. Arendt LH, Henriksen TB, Lindhard MS, Parner E, Olsen J, Ramlau-Hansen $\mathrm{CH}$. Hypertensive disorders of pregnancy and genital anomalies in boys: a Danish Nationwide cohort study. Epidemiology. 2018;29:739-48.

16. Boyd HA, Basit S, Behrens I, Leirgul E, Bundgaard H, Wohlfahrt J, Melbye M, Øyen N. Association between fetal congenital heart defects and maternal risk of hypertensive disorders of pregnancy in the same pregnancy and across pregnancies. Circulation. 2017;136:39-48.

17. Thilaganathan B. Placental syndromes: getting to the heart of the matter. Ultrasound Obstet Gynecol. 2017:49:7-9.

18. Thilaganathan B. Preeclampsia and fetal congenital heart defects: spurious association or maternal confounding? Circulation. 2017;136:49-51.

19. Yang M, Fan XB, Wu JN, Wang JM. Association of assisted reproductive technology and multiple pregnancies with the risks of birth defects and stillbirth: a retrospective cohort study. Sci Rep. 2018;8:8296.

20. Bhide A, Acharya G, Bilardo CM, Brezinka C, Cafici D, Hernandez-Andrade E, Kalache K, Kingdom J, Kiserud T, Lee W, Lees C, Leung KY, Malinger G, Mari G, Prefumo F, Sepulveda W, Trudinger B. ISUOG practice guidelines: use of Doppler ultrasonography in obstetrics. Ultrasound Obstet Gynecol. 2013;41:233-9.

21. Zhang WY, Yang Z, Lin JH, et al. The gestational hypertension disease group of Chinese medical association obstetrics and gynaecology branch. The guidelines for the Management of Hypertensive Disorders of pregnancy. Chin J Obstet Gynecol. 2015:50:721-8.

22. Auger N, Fraser WD, Healy-Profitos J, Arbour L. Association between preeclampsia and congenital heart defects. JAMA. 2015;314:1588-98.

23. Wu JN, Gu WR, Xiao XR, Zhang Y, Li XT, Yin CM. Gestational weight gain targets during the second and third trimesters of pregnancy for women with gestational diabetes mellitus in China. Eur J Clin Nutr. 2019;73(8):1155-63.

24. Buis ML. Direct and indirect effects in a logit model. Stata J. 2010;10:11-29.

25. Ghazarian AA, Trabert B, Graubard BI, Longnecker MP, Klebanoff MA, McGlynn KA. Placental weight and risk of cryptorchidism and hypospadias in the collaborative perinatal project. Am J Epidemiol. 2018;187:1354-61.

26. Carbone IF, Cruz JJ, Sarquis R, Akolekar R, Nicolaides KH. Assisted conception and placental perfusion assessed by uterine artery Doppler at 11-13 weeks' gestation. Hum Reprod. 2011;26:1659-64.

27. Geipel A, Hennemann F, Fimmers R, Willruth A, Lato K, Gembruch U, Berg C. Reference ranges for Doppler assessment of uterine artery resistance and pulsatility indices in dichorionic twin pregnancies. Ultrasound Obstet Gynecol. 2011;37:663-7. 
28. Brosens I, Pijnenborg R, Vercruysse L, Romero R. The "great obstetrical syndromes" are associated with disorders of deep placentation. Am J Obstet Gynecol. 2011;204:193-201.

29. Balci A, Sollie KM, Mulder BJ, de Laat MWM, Roos-Hesselink JW, van Dijk APJ, Wajon EMC, Vliegen HW, Drenthen W, Hillege HL, Aarnoudse JG, van Veldhuisen DJ, Pieper PG. Associations between cardiovascular parameters and uteroplacental Doppler (blood) flow patterns during pregnancy in women with congenital heart disease: Rationale and design of the Zwangerschap bij Aangeboren Hartafwijking (ZAHARA) II study. Am Heart J. 2011;161:269-275.e1.

30. Plasencia W, Maiz N, Bonino S, Kaihura C, Nicolaides KH. Uterine artery Doppler at $11+0$ to $13+6$ weeks in the prediction of pre-eclampsia. Ultrasound Obstet Gynecol. 2007;30:742-9.

31. Akolekar R, Syngelaki A, Poon L, Wright D, Nicolaides KH. Competing risks model in early screening for preeclampsia by biophysical and biochemical markers. Fetal Diagn Ther. 2013;33:8-15.

32. Poon LC, Syngelaki A, Akolekar R, Lai J, Nicolaides KH. Combined screening for preeclampsia and small for gestational age at 11-13 weeks. Fetal Diagn Ther. 2013;33:16-27.

33. O'Gorman N, Wright D, Syngelaki A, Akolekar R, Wright A, Poon LC, Nicolaides $\mathrm{KH}$. Competing risks model in screening for preeclampsia by maternal factors and biomarkers at 11-13 weeks gestation. Am J Obstet Gynecol. 2016;214:103 e1-12.

34. Haavaldsen C, Samuelsen SO, Eskild A. Fetal death and placental weight/ birthweight ratio: a population study. Acta Obstet Gynecol Scand. 2013;92:583-90

35. Strøm-Roum EM, Haavaldsen C, Tanbo TG, Eskild A. Placental weight relative to birthweight in pregnancies with maternal diabetes mellitus. Acta Obstet Gynecol Scand. 2013:92:783-9.

36. Rodriguez M, Couve-Pérez C, San Martin S, Martinez F, Lozano C, SepulvedaMartinez A. Perinatal outcome and placental apoptosis in patients with lateonset pre-eclampsia and abnormal uterine artery Doppler at diagnosis. Ultrasound Obstet Gynecol. 2018;51:775-82.

37. Weidner IS, Møller H, Jensen TK, Skakkebaek NE. Risk factors for cryptorchidism and hypospadias. J Urol. 1999;161:1606-9.

38. Jensen MS, Wilcox AJ, Olsen J, Bonde JP, Thulstrup AM, Ramlau-Hansen CH, Henriksen TB. Cryptorchidism and hypospadias in a cohort of 934,538 Danish boys: the role of birth weight, gestational age, body dimensions, and fetal growth. Am J Epidemiol. 2012;175:917-25.

39. Everett TR, Lees CC. Beyond the placental bed: placental and systemic determinants of the uterine artery Doppler waveform. Placenta. 2012;33:893-901.

40. Schnack TH, Zdravkovic S, Myrup C, Westergaard T, Christensen K, Wohlfahrt J, Melye M. Familial aggregation of hypospadias: a cohort study. Am J Epidemiol. 2008;167:251-6.

41. Stoll C, Alembik Y, Roth MP, Dott B. Genetic and environmental factors in hypospadias. J Med Genet. 1990;27:559-63.

42. Harris EL. Genetic epidemiology of hypospadias. Epidemiol Rev. 1990;12:29-40.

43. Verbitsky M, Westland R, Perez A, et al. The copy number variation landscape of congenital anomalies of the kidney and urinary tract. Nat Genet. 2019;51:117-27.

44. Campana H, Rittler M, Gili JA, Poletta FA, Pawluk MS, Gimenez LG, Cosentino VR, Castilla EE, Camelo JS. Association between a maternal history of miscarriages and birth defects. Birth Defects Res. 2017;109:254-61.

45. Thomas EG, Toufaily MH, Westgate MN, Hunt AT, Lin AE, Holmes LB. Impact of elective termination on the occurrence of severe birth defects identified in a hospital-based active malformations surveillance program (1999 to 2002). Birth Defects Res A Clin Mol Teratol. 2016;106:659-66.

\section{Publisher's Note}

Springer Nature remains neutral with regard to jurisdictional claims in published maps and institutional affiliations.

Ready to submit your research? Choose BMC and benefit from:

- fast, convenient online submission

- thorough peer review by experienced researchers in your field

- rapid publication on acceptance

- support for research data, including large and complex data types

- gold Open Access which fosters wider collaboration and increased citations

- maximum visibility for your research: over $100 \mathrm{M}$ website views per year

At BMC, research is always in progress.

Learn more biomedcentral.com/submissions 